University of Wollongong

Research Online

Faculty of Engineering and Information

Faculty of Engineering and Information

Sciences - Papers: Part A

Sciences

$1-1-2014$

\title{
The effect of ageing on microstructure and mechanical properties of powder Ti-5Al-5Mo-5V-1Cr-1Fe alloy
}

\author{
Mansur Ahmed \\ University of Wollongong, ma960@uowmail.edu.au \\ Dmytro Savvakin \\ National Academy of Sciences, Ukraine \\ Orest M. Ivasishin \\ National Academy of Sciences, Ukraine \\ E V. Pereloma \\ University of Wollongong, elenap@uow.edu.au
}

Follow this and additional works at: https://ro.uow.edu.au/eispapers

Part of the Engineering Commons, and the Science and Technology Studies Commons 


\title{
The effect of ageing on microstructure and mechanical properties of powder Ti-5Al-5Mo-5V-1Cr-1Fe alloy
}

\begin{abstract}
The thermo-mechanically processed powder Ti-5Al-5V-5Mo-1Cr-1Fe alloy was aged at $9.23 \mathrm{~K}$ for $1-8 \mathrm{~h}$ in order to investigate the effect of ageing time on the microstructure-mechanical properties relationships. The microstructures of the alloy after ageing cosist of the both primary and secondary alpha phases with retained $B$ matrix phase. The shift of $B$ peaks in X-ray pattern with ageing time indicates an increase in lattice parameter distorition due to diffusion into the retained $B$ phase of more $B$ stabilisers with smaller atomic radius compared to the elemental Ti. The tensile test results indicate that the sample aged for $1 \mathrm{~h}$ has achieved the best combination of mechanical properties with ultimate tensile strength of $1194 \mathrm{MPa}$ and total elongation of $14 / 1 \%$ among all the experimented conditioins. The modified Crussard-Jaoul method is applied to characterise the work hardening behaviour of the alloy.
\end{abstract}

\section{Keywords}

$1 \mathrm{fe}, 1 \mathrm{cr}, 5 \mathrm{v}, 5 \mathrm{mo}, 5 \mathrm{al}$, ti, powder, alloy, properties, effect, mechanical, microstructure, ageing

Disciplines

Engineering | Science and Technology Studies

\section{Publication Details}

Ahmed, M., Savvakin, D. G., Ivasishin, O. M. \& Pereloma, E. (2014). The effect of ageing on microstructure and mechanical properties of powder Ti-5Al-5Mo-5V-1Cr-1Fe alloy. Materials Science and Engineering A, 605 (May), 89-97. 


\title{
The effect of ageing on microstructure and mechanical properties of powder Ti-5Al-5Mo-5V-1Cr-1Fe alloy
}

\author{
Mansur Ahmed a, *, Dmytro G. Savvakin b, Orest M. Ivasishin b, Elena V. Pereloma a, c \\ a School of Mechanical, Materials \& Mechatronic Engineering, University of Wollongong, NSW \\ 2522, Australia \\ b Institute for Metal Physics, National Academy of Sciences of Ukraine, UA-03142 Kiev, \\ Ukraine \\ c Electron Microscopy Centre, University of Wollongong, NSW 2519, Australia
}

\begin{abstract}
:
The thermo-mechanically processed powder Ti-5Al-5V-5Mo-1Cr-1Fe alloy was aged at $923 \mathrm{~K}$ for 1-8 $\mathrm{h}$ in order to investigate the effect of ageing time on the microstructure-mechanical properties relationships. The microstructures of the alloy after ageing consist of the both primary and secondary $\alpha$ phase with retained $\beta$ matrix phase. The shift of $\beta$ peaks in X-ray pattern with ageing time indicates an increase in lattice parameter distortion due to diffusion into the retained $\beta$ phase of more $\beta$ stabilisers with smaller atomic radius compared to the elemental Ti. The tensile test results indicate that the sample aged for $1 \mathrm{~h}$ has achieved the best combination of mechanical properties with ultimate tensile strength of $1194 \mathrm{MPa}$ and total elongation of $14.1 \%$ among all the experimented conditions. The modified Crussard-Jaoul method is applied to characterise the work hardening behaviour of the alloy.

Keywords: powder Ti-55511, ageing, microstructure, X-ray diffraction, mechanical properties.

${ }^{*}$ Corresponding author: Mansur Ahmed

E-mail: ma960@uowmail.edu.au
\end{abstract}

Tel: +61242215798

Fax: +61242213662 


\section{Introduction:}

The main reasons for using Ti alloys in the fields of aerospace, chemical and medical applications are their high strength with reasonable ductility, high strength-to-weight ratio, good fatigue strength and corrosion resistance [1]. The conventional casting is so far the most commonly used method for the production of Ti alloys for different aerospace parts, e.g. landing gears, airframe, compressor discs and blades, spacers and gas turbine engines [2, 3]. However, castings inherit some essentially unavoidable defects, such as macro-segregation, microsegregation, porosity, solidification shrinkage and second phase inclusions [3-5]. In addition, only $\sim 10 \%$ of the material's initial weight is utilised [6] resulting in high processing costs. On the other hand, powder metallurgy provides a significant cost reduction in the production of $\mathrm{Ti}$ alloys [7, 8] making them more affordable, which may lead to a wider spread of their applications in many fields. Moreover, using powder metallurgy technique nearly full density products could be manufactured [8,9]. The blended elemental powder metallurgy (BEPM) technique is one of the cost effective technique for production Ti alloys $[7,8]$.

Microstructure of near- $\beta$ Ti alloys (e.g. Ti-5Al-5Mo-5V-1Cr-1Fe (Ti-55511)) consists of $\alpha$ and $\beta$ phase where the amount and morphology of $\alpha$ phase to a large extent control the mechanical properties [10]. Moreover, heat treatment is used to modify the microstructure of this category alloys. Ageing is the final and inevitable processing step which is used to improve the mechanical properties [10]. Ageing of Ti-55511 is usually performed at high temperature ( $>623 \mathrm{~K}$ ) where preferable nucleation sites for $\alpha$ nucleation already exist such as dislocations, or metastable $\omega$ phase [11]. Ohmori et al. [12] have mentioned that $\alpha$ precipitates nucleate at $\omega / \beta$ interfaces, whereas Zhang et al. [13] have reported that fine $\alpha$ phase nucleates at $\omega$ particles. This $\omega$ phase is formed during slow heating to ageing temperature [14]. Nag et al. [15] have noticed that $\omega$ phase is very fine nanometre sized precipitates and the elemental concentration variation is considered to be responsible for its formation. Thus, the availability of such large number of nucleation sites results in fine $\alpha$ precipitation which is associated with both high strength and ductility [16]. Hence, high temperature ageing with slow heating rate to ageing temperature has been used in the present study.

Most of the previous investigations mentioned only the mechanical properties of cast Ti55511 alloy during ageing [11, 17-21], while some others reported only microstructural changes without providing data on the mechanical properties [13, 22]. Mechanical properties of cast/wrought Ti-55511 alloy after ageing at different conditions are listed in Table 1; they are dependent on the complete processing schedule. Although a limited data on the microstructuremechanical properties relationships of aged (cast/wrought) Ti-55511 is available [14, 23], the detailed and systematic analysis of these relationships is lacking. Thus, the aim of the present 
study is to evaluate the effect of ageing time on the microstructure-mechanical properties relationships of Ti-55511 alloy produced by cost effective (BEPM) process.

\section{Materials and Experiments:}

In order to obtain the required alloy composition, Ti powders containing $3.5 \mathrm{wt} . \%$ hydrogen were combined with elemental $\mathrm{Mo}, \mathrm{Cr}, \mathrm{Fe}(<40 \mu \mathrm{m})$ and 50Al-50V master alloy powders (40-63 $\mu \mathrm{m})$. Thereafter the green compacts were prepared through blending and die pressing under $650 \mathrm{MPa}$. The sintering of green compacts was done by two steps (i) heating to $1293 \mathrm{~K}$ for $1 \mathrm{~h}$ followed by (ii) heating to $1523 \mathrm{~K}$ for $6 \mathrm{~h}$ to assist the distribution of the alloying elements homogeneously in the matrix. The as-sintered material contains of about $2 \%$ vol. residual porosity which was determined using the Archimedes method [24] .

Thermo-mechanical processing (TMP) was conducted using a Gleeble 3500 thermomechanical simulator. Tests were carried out under $\sim 3.8 \times 10^{-4}$ torrs vacuum to avoid atmospheric contamination. The dimensions of the cylindrical sample used for the TMP was 12 $\mathrm{mm}$ length and $8 \mathrm{~mm}$ diameter. The samples were heated to $1223 \mathrm{~K}$ at $10 \mathrm{Ks}^{-1}$ and held for 120 s. Afterwards, the samples were cooled down to $1173 \mathrm{~K}$ at $35 \mathrm{Ks}^{-1}$ and deformed to $25 \%$ reduction followed by cooling to $1073 \mathrm{~K}$ at $35 \mathrm{Ks}^{-1}$. Thereafter the samples were held for $600 \mathrm{~s}$ at $1073 \mathrm{~K}$ followed by $60 \%$ reduction at $1073 \mathrm{~K}$. Eventually, the samples were cooled to room temperature at $10 \mathrm{Ks}^{-1}$. After the TMP, the samples were encapsulated into a quartz tube under vacuum in order to protect against high temperature oxidation. Thereafter, the samples were placed into a tube furnace ${ }^{2}$ and heated at $0.25 \mathrm{Ks}^{-1}$ to $923 \mathrm{~K}$ and held for $1 \mathrm{~h}, 2 \mathrm{~h}, 4 \mathrm{~h}$ and $8 \mathrm{~h}$. The entire heat treatment cycle is shown in Fig. 1.

The microstructures were investigated using scanning electron microscopy (SEM). The specimens for SEM observations were cut normal to the deformation direction and prepared by using conventional metallographic techniques. After polishing, the samples were etched in a solution of $2 \mathrm{ml}$ hydrofluoric acid, $5 \mathrm{ml}$ nitric acid and $93 \mathrm{ml}$ distilled water (Kroll's reagent) to reveal the microstructure. SEM observations were carried out using a JEOL-JSM 7001F Field Emission Gun-Scanning Electron Microscope (FEG-SEM) operating at $15 \mathrm{kV}$ voltage and $10 \mathrm{~mm}$ working distance and equipped with an XMax Oxford Instruments energy dispersive X-ray spectrometer (EDS). The sub-sized tensile test specimens with gauge length $5.1 \mathrm{~mm}$; width 2.18 $\mathrm{mm}$ and thickness $0.9 \mathrm{~mm}$ were machined using the electrical discharge machine (EDM). A $\mu$ Tweezer Tensile Module ${ }^{3}$ at a constant speed of $1.7 \mathrm{~mm} \mathrm{~min}^{-1}$ at room temperature was used to perform the tensile test. The stress-strain curves were fitted using rational polynomial functions

\footnotetext{
${ }^{1}$ Dynamic Systems Inc.

${ }^{2}$ GSL-1600-80X, MTI Corporation

${ }^{3}$ Kammrath \& Weiss, GmbH
} 
(via a programme called TableCurve5.1) which were utilised to find the m-values of the plastic regions of the samples.

A PANalytical X'Pert PRO Multipurpose diffractometer (MPD) with $\mathrm{Cu}$ Ka radiation $(\lambda=0.154 \mathrm{~nm})$ filtered with $\mathrm{Ni}$-monochromator operating at $45 \mathrm{~mA}$ and $40 \mathrm{kV}$ was used to investigate the material using X-ray diffraction. The dimension of the samples was $\sim 15 \mathrm{~mm}$ diameter which were oriented parallel to the deformation axis. Under a continuous scanning mode, the diffraction patterns were acquired over the $2 \theta$ range of $30^{\circ}$ to $90^{\circ}$. The step size and the acquisition time were $0.01^{\circ}$ and 490 s respectively. A standard polycrystalline silicon sample was used in order to characterise the instrumental broadening. The lattice parameters of the hcp crystal structure were calculated precisely using Cohen's method [25]. The volume fraction of $\alpha$ phase was calculated using direct comparison method [25]. The Rietveld method was applied to characterise the different crystallographic planes (e.g. crystallite size and microstrain) of $\alpha$ and $\beta$ phases using X'pert HighScore Plus software. The algorithms behind Rietveld method used in the present study are described elsewhere [26]. Thereafter, the dislocation density of the crystallographic planes was calculated from the numerical value of crystallite size and microstrain using the standard equations [27, 28].

\section{Results and discussion:}

\subsection{The evolution of microstructure:}

After TMP, the microstructure of Ti-55511 alloy consists of primary $\alpha$ and $\beta$ phases (Fig. 2a). This condition has been used as ageing precursor. $\alpha$ phase has different morphologies in TMP sample: globular and lamellae which forms basket weave structure. The fragmentation of grain boundary $\alpha$ occurs during high temperature deformation at $1073 \mathrm{~K}$. Partial $\beta$ recrystallisation and fine $\alpha$ lamellae were produced during cooling to room temperature, which has also been reported in [27]. From XRD data, the volume fraction of $\alpha$ phase was calculated to be $26 \pm 4 \%$, so that the microstructure can further be optimised during ageing.

Figs. $2 \mathrm{~b}$-e show the microstructures of Ti-55511 alloy after ageing at $923 \mathrm{~K}$ for $1 \mathrm{~h}, 2 \mathrm{~h}, 4 \mathrm{~h}$ and 8 h, respectively. The microstructures consist basically of primary $\alpha$, secondary $\alpha$ and retained $\beta$ phases. The morphology of the secondary $\alpha$ phase precipitated during ageing is shown in Figs. 2 and 3. It is evident that recrystallisation of the deformed $\beta$ phase occurs during ageing (Figs. 3be). Similarly, the recrystallisation of deformed $\beta$ phase is reported in [29]. It appears that the morphology of fine secondary $\alpha$ is almost similar for all the aged samples showing basket weave structure which precipitated homogeneously. It also shows that the fine secondary $\alpha$ precipitated both intragranularly and at the grain boundaries of recrystallised $\beta$ phase which supports the investigation by Zhang et al. [13]. The applied high temperature deformation 
increases the dislocation density of $\beta$ phase as glide occurs easily in bcc structure, thus resulting in more nucleation sites for $\alpha$ precipitates $[27,30]$. The amount of fine secondary $\alpha$ phase is the identifying difference among the aged samples, as it increases with ageing time from $44 \%$ after $1 \mathrm{~h}$ to $62 \%$ after $8 \mathrm{~h}$ ageing (Table 2). The width and length of fine secondary $\alpha$ for $1-4 \mathrm{~h}$ aged samples are 0.08-0.12 $\mu \mathrm{m}$ and $\sim 0.6 \mu \mathrm{m}$, correspondingly. On the other hand, fine secondary $\alpha$ in the sample aged for $8 \mathrm{~h}$ has grown by coalescing adjacent $\alpha$ lamellae (Fig. $3 \mathrm{~d}$ ) which returned the width and length of $\sim 0.2$ and $0.5 \mu$ m respectively. Since nucleation and growth of fine secondary $\alpha$ is a continuous process, the growth seems dominant after $4 \mathrm{~h}$ ageing. It is mentioned in [22], that the growth of the $\alpha$ phase could be due to (i) the increase of diffusional mobility of atoms at the temperature of ageing and (ii) the need to decrease surface-to-volume ratio of needle-like $\alpha$ particles in order to reduce the total energy of the system. In the present study no $\alpha$ " phase appears contrarily to the findings by Shevel'kov [22], because shorter ageing times used were not sufficient to produce large concentration gradients within $\beta$ phase. The obtained microstructures are in good agreement with the existing literature [13, 14, 31, 32]. Beyond this, there is an important microstructural feature showing the incomplete phase transformation in a single $\alpha$ lamellae (Fig. 3b, d). The similar result is also obtained in our previous investigation [27] where it has been proved that the segregation of $C$ and/or $O$ is responsible for this event. As $\mathrm{C}$ and 0 are $\alpha$ stabilisers, formation of their segregation into the $\beta$ matrix reduce Mo equivalent. Thus, such local region is more stable $\beta$ (due to the increased $\beta$ transus temperature [33]) resulting in a delay in the $\beta \rightarrow \alpha$ transformation compared to the area containing no $\mathrm{C}$ and/or $\mathrm{O}$ segregation.

White spherical shaped particles of typically $100-200 \mathrm{~nm}$ in size are present in the microstructures in both $\alpha$ and $\beta$ phases (Fig. 3). However, some of them reach up to $1 \mu \mathrm{m}$ size (Fig. 3e inset). From the comparison of EDS spectra of $\beta$ matrix and a white particle, it is clear that the main elements in the particle are titanium and carbon. Thus, it is assumed to be a titanium carbide particle (Fig.3e). There is no effect of ageing on these particles in terms of their size and morphology (Fig. 3). The presence of similar white titanium carbide particles in $\beta$ Ti alloys is reported in the literature [20,32, 34]. In another study [35], the effect of carbon content on structural changes in $\alpha$ phase in Ti-5Al-5Mo-5V-3Cr alloy has been discussed but they do not mention the presence of such particles. The reason for titanium carbide formation can be understood from the electronic configuration of Ti i.e. [Ar] $3 \mathrm{~d}^{2} 4 \mathrm{~s}^{2}$. Sung and Tai [36] have reported that transition metals react with carbon by overlapping their d-orbitals with carbon p-orbitals, and thus the reactivity of carbon and metals is mainly determined by metal electronic state and specifically by number of vacant electron in d-orbitals. In the present case, as the number of the electron vacancy in d-orbitals in titanium increases compared to other elements $(\mathrm{Mo} / \mathrm{V} / \mathrm{Cr} / \mathrm{Fe})$, the reactivity also increases which lead to the formation of titanium 
carbide. This is why titanium carbide can easily form depending upon the availability of carbon. In the present study, carbon may be picked up unexpectedly during either processing (TMP/ageing) or from the original powder.

\subsection{Phase composition and their dependency on the elemental diffusion:}

The compositional variation of the phases with respect to the ageing time is depicted in Fig. 4. It is clear from the histogram for primary $\alpha$ that the amount of the $\beta$ stabilising alloying elements depletes with the ageing time whereas the concentration of $\alpha$ stabiliser Al increases (Fig. 4a). This is attributed to the diffusion of the $\beta$ stabilisers out of the primary $\alpha$ phase. The observed increase in the concentration of $\beta$ stabilising elements in fine secondary $\alpha$ with increase in ageing time is associated with the formation of secondary $\alpha$ from more enriched $\beta$ phase. As $\beta$ stabilisers diffuse out of fine secondary $\alpha$ formed during ageing, the $\beta$ phase becomes enriched. This enriched retained $\beta$ phase acts as the parent phase for producing secondary $\alpha$ at later stages of ageing. Consequently, each secondary $\alpha$ produced at the next stage of ageing has more $\beta$ stabilisers than the previous one (Fig. 4).

Solid state diffusion is the mechanism responsible for mass transfer resulting in the observed compositional difference in the phases with the ageing time. The effective diffusion distance of an element can be estimated by the following equation [37]:

$x=\sqrt{D t}$

Where, $x$ is the effective diffusion distance (or path), $D$ is the diffusivity of element herein and $t$ is the diffusion time. The diffusivity $D$ of an element depends upon the temperature and activation energy which also varies with the temperature. However, the diffusivity can be calculated using the following equation [38]:

$D=D_{0} \exp (-Q / R T)$

Where, $D_{0}$ is the pre-exponential diffusion constant, $Q$ is the activation energy for diffusion, $T$ is the diffusion temperature and $R$ is the ideal gas constant. Using the above Eq. 1 and 2, the diffusion distances for $\mathrm{Fe}$ and $\mathrm{Cr}$ has been estimated in $\alpha$-Ti at ageing temperature ( $923 \mathrm{~K}$ ). The calculated diffusion path for $\mathrm{Fe}$ is $12.8-27.3 \mu \mathrm{m}$ for $1 \mathrm{~h}$ using the following range for $\mathrm{Fe}$ diffusivity $D=4.54 \times 10^{-14}$ to $2.08 \times 10^{-13} \mathrm{~m}^{2} \mathrm{~s}^{-1}$ [38]. Furthermore, for similar condition the estimated diffusion distance for $\mathrm{Cr}$ is $1.37-1.85 \mu \mathrm{m}$ when $D=5.18 \times 10^{-16}$ to $9.48 \times 10^{-16} \mathrm{~m}^{2} \mathrm{~s}^{-1}$ [38]. Unfortunately, there is no diffusivity information available for $\mathrm{V}$ and Mo in $\alpha$-Ti. On the other hand, the effective diffusion distance for $\mathrm{Al}$ in $\beta$-Ti is $0.2 \mu \mathrm{m}$ for similar condition using $D=$ $9.94 \times 10^{-18} \mathrm{~m}^{2} \mathrm{~s}^{-1}[38]$. Considering the concentration of $\mathrm{Fe}$ and $\mathrm{Cr}$ in primary $\alpha$ phase, it can easily be realised that the actual diffusion distance is reasonably shorter than the calculated one (12.8$27.3 \mu \mathrm{m}$ and 1.37-1.85 $\mu \mathrm{m}$ after $1 \mathrm{~h}$, respectively) because primary $\alpha$ phase has width of 0.4-0.6 
$\mu \mathrm{m}$ and some Fe and $\mathrm{Cr}$ are still remained in it (Fig. 4a). This is attributed to the reduction of the diffusivity of the elements when more than one elements present in the system [39].

\subsection{Materials characterisation using XRD line profile analysis:}

Fig. 5 indicates the X-ray diffraction profiles and corresponding Rietveld fitting for all the conditions where peaks from $\alpha$ and $\beta$ phases with Miller-Bravis indices are clearly displayed. The difference in intensity between Rietveld fitting and experimental has also been plotted under each profile. The agreement indices of the fitting show that the residual weighted profile remains between $10-15 \%$ for all samples whereas the Goodness of fit is lying close to 1 . A summary of the Rietveld fitting representing crystallite size, microstrain, and dislocation density for $\beta$ and $\alpha$ phases with respect to ageing time are shown in Tables 3 and 4 respectively. A reduction in dislocation densities in both phases has been occurred during ageing compared to TMP condition. The following two concurrent events determines the density of dislocations within $\beta$ planes: (i) the plastically deformed $\beta$ planes have relaxed/reduced stress during ageing through the recrystallisation and (ii) the fine secondary $\alpha$ produced during ageing have constrained the $\beta$ phase. On the other hand, the first event dominates in the $\alpha$ phase resulting in a reduction in density of dislocations with the ageing time. The observed difference in the density of dislocations between two phases can also be explained by the evolvement of fine secondary $\alpha$ through constraining $\beta$ which plays a significant role in the increase of dislocation density in $\beta$ phase. As expected, the crystallographic plane $\beta(110)$ has the maximum dislocation density and $\beta$ (200) has the minimum in all the conditions. It is mentioned in [40] that $\beta(110)$ planes has the maximum compliance of strain during deformation whereas $\beta$ (200) has the lowest among the bcc planes in metastable $\beta$ alloy resulting in the highest dislocation density in $\beta(110)$.

Table 5 presents the data of the lattice parameters of the $\beta$-Ti and $\alpha$-Ti. It has been mentioned in [27] that the $\beta$ lattice parameter reduced after TMP compared to unalloyed Ti. The presence of $\beta$ stabilisers which have smaller atomic radii compared to elemental Ti is responsible for this event. A further reduction in $\beta$ lattice parameter from 0.32 to $0.30 \mathrm{~nm}$ is obtained during ageing compare to the TMP condition, which can also be explained by the same reason because the $\beta$ phase becomes more supersaturated with the same alloying elements. However, there was no significant effect of the ageing time on the lattice parameters of hcp crystal ( $\alpha$-Ti) because $\alpha$ stabiliser $\mathrm{Al}(143 \mathrm{pm})$ is the main alloying element in hcp lattice which has a closer atomic radius to Ti (147 $\mathrm{pm}$ ) compared to those of $\beta$ stabilising alloying elements.

\subsection{Mechanical Properties:}


A summary of the mechanical properties derived from the Fig. 6 is given in Table 2. The volume fraction of $\alpha$ is linearly proportional to the ageing time which ultimately affects the tensile properties. The samples aged for $8 \mathrm{~h}$ and $1 \mathrm{~h}$ have yielded the maximum UTS (1298 $\pm 16 \mathrm{MPa})$ and the minimum UTS $(1194 \pm 24 \mathrm{MPa})$, respectively. Contrarily, the maximum total elongation $(14 \pm 1 \%)$ and the minimum total elongation $(10 \pm 1 \%)$ are obtained for the samples aged for $1 \mathrm{~h}$ and $8 \mathrm{~h}$, respectively. The increasing trend of the strength and the decreasing one for the elongation with respect to $\alpha$ volume fraction support the second phase precipitation hardening mechanism. The obtained strength-elongation results are in good agreement with the literature [11, 14, 17, 31]. Ivasishin et al. [14] have obtained UTS of $1410 \mathrm{MPa}$ and elongation of 7.5-10\% after ageing at $913 \mathrm{~K}$ for $8 \mathrm{~h}$. The difference in UTS and elongation between the present study and ref. [14] can be explained by analysing the heat treatment cycle of both samples. They heated the sample to $1223 \mathrm{~K}$ ( $\beta$ solution treatment) for $0.5 \mathrm{~h}$ resulting in a large $\beta$ grain size $(\sim 200 \mu \mathrm{m})$ whereas in the present study only $300 \mathrm{~s}$ holding at the same temperature yielded much smaller $\beta$ grain size ( $\sim 80 \mu \mathrm{m}$ [41]). Thereafter, the sample of ref. [14] was cold deformed leading to $\alpha^{\prime \prime}$ formation and causing poor elongation [42]. In contrast, in the present study hot plastic deformation (60\%) at $1073 \mathrm{~K}$ is applied which fragments the primary $\alpha$ phase. It is well known that the fragmentation of $\alpha$ assists in improving the ductility of Ti. The reason behind obtaining such a good combination of total elongation (10-14\%) and ultimate tensile strength (1200-1300 MPa) was the slow heating rate $\left(0.25 \mathrm{Ks}^{-1}\right)$ to the ageing temperature. Since the slower heating rate offers the $\beta$ phase decomposition to $\alpha$ through $\omega$ e.g. $\beta \rightarrow \beta+\omega \rightarrow \alpha+$ $\beta$ rather than direct $\beta$ phase decomposition at higher heating rate $\left(20 \mathrm{Ks}^{-1}\right)[14,43]$ resulting in well dispersed, fine and uniform intragranular $\alpha$ phase which enhance both the strength and elongation. In contrast, higher heating rate leads to a coarser and non-uniformly distributed $\alpha$ precipitates resulting in poor balance of mechanical properties [14, 31].

The effect of the titanium carbide particles on the mechanical properties is mentioned in [20, 32]. It has been shown that the addition of $C$ reinforces the strength and reduces the elongation slightly due to the formation of titanium carbide compound. It is rather difficult to comment about the contribution of the titanium carbide particles to the mechanical properties in the present study, because $\mathrm{C}$ is not added deliberately and the total $\mathrm{C}$ amount is negligible. On the other hand, the presence of titanium carbide can enhance the high temperature strength, i.e. creep properties of an alloy [20,32]. Since the melting temperature of titanium carbide particles is $3800 \mathrm{~K}$ and they remain stable at high temperature, thus they will render strength at high temperature application. 
The modified Crussard - Jaoul (C-J) model [44-48], which is developed to analyse work hardening $(\mathrm{WH})$ behaviour of materials containing two phases, is utilised in the present study. The modified C-J model uses the following Swift equation (Eq. 3) for the analysis [44]:

$\varepsilon=\varepsilon_{0}+\mathrm{C}_{\mathrm{s}} \sigma^{\mathrm{m}}$

Where, $\sigma$ is true stress, $\varepsilon$ is true strain, $\mathrm{m}$ is $\mathrm{WH}$ exponent and $\mathrm{C}_{\mathrm{s}}$ is material constant. The logarithmic form of the differential Swift equation with respect to strain $(\varepsilon)$ provides the following Eq. 4:

$\ln (\mathrm{d} \sigma / \mathrm{d} \varepsilon)=(1-\mathrm{m}) \ln \sigma-\ln \left(\mathrm{C}_{\mathrm{s}} \mathrm{m}\right)$

Eq. 4 represents the linear relationship between logarithmic form of WH rate, $\ln (\mathrm{d} \sigma / \mathrm{d} \varepsilon)$, and logarithmic form of true stress, $\ln \sigma$, where $(1-\mathrm{m})$ is slope of the line. The logarithm of WH rate, $\ln (d \sigma / d \varepsilon)$, versus logarithm of true stress, $\ln \sigma$, is plotted for all the ageing conditions in Fig. 7. The curves have been fitted using Pearson IV (a, b, c, d, e, f) equation are also included in Fig 7. Each of the curves is segmented into three distinct stages as per depicted in Fig. 7 (stage I, stage II and stage III), with a maximum slope in stage II and a minimum one in stage III. It is noticeable that the duration of stage I is shortened with the ageing time, which is explained below. A summary of the results obtained from Fig. 7 is presented in Table 6, where the WH exponent $(\mathrm{m})$ values corresponding to the each stage are given together with the transition true stress and true strain values. The maximum value of the $m$ value is obtained for stage II ( $\left.m_{I I}\right)$ and the minimum $\mathrm{m}$ value is obtained for stage III $\left(\mathrm{m}_{\text {III }}\right)$ in all the samples. It is mentioned in $[46,47]$ that three stages in the WH behaviour depend upon the amount and type of the phases present in the microstructure. Stage I corresponds to the plastic deformation of $\beta$ phase through gliding of dislocations. The dislocations in the $\beta$ phase pile up in the vicinity of $\alpha / \beta$ interfaces and grain or laths boundaries, which act as barriers to the dislocation movement. This creates the strain gradient between the $\alpha$ crystals and $\beta$ phase itself. However, $\alpha$ phase does not deform at this stage. The longevity of stage I depends on the amount of $\alpha$ phase. The higher the amount of $\alpha$ phase indicates the shorter free path for dislocation movement in the $\beta$ phase, which ultimately reduces the duration of stage I. Once the $\beta$ phase is work hardened, load transfers to $\alpha$ phase which undergoes elastic deformation of the phase (stage II). Raghunathan et al [49] have also mentioned that fine secondary $\alpha$ lamellae significantly strengthen the material through increasing the strength of $\beta$ phase by dislocation pining by fine secondary $\alpha$. In the present study, secondary $\alpha$ phase is too large to pin dislocations so hardening was obtained through dislocation gliding where $\alpha$ lamellae serve as barrier. Stage III corresponds to the plastic deformation of hard $\alpha$ phase.

\section{Conclusions:}


In the present study, the influence of the ageing time $(1 \mathrm{~h}, 2 \mathrm{~h}, 4 \mathrm{~h}$, and $8 \mathrm{~h})$ at a constant temperature of $923 \mathrm{~K}$ is reported in terms of microstructural characterisation and mechanical properties of a powder Ti-5Al-5Mo-5V-1Cr-1Fe (VT22) alloy. The following conclusions can be drawn from this study:

o The microstructures illustrate a progression over the ageing time e.g. fine secondary $\alpha$ lamellae phase were formed. The amount of $\alpha$ phase increased over the ageing period. The microstructures contain some particles of titanium carbide due to unintentional pick up of $\mathrm{C}$ during processing.

o The evolution of phase compositions with ageing reflects that $\beta$ stabilisers diffuse out of primary and fine secondary $\alpha$ phase into the retained $\beta$ phase, whereas $\mathrm{Al}$ diffuses out of $\beta$ phase being $\alpha$ stabiliser.

o XRD data shows reduction in dislocation density as a result of relaxation processes (recovery and recrystallisation) taking place during ageing.

o The longer the ageing time, the more secondary $\alpha$ is formed resulting in increase in UTS and decrease in total elongation. A good combination of strength and total elongation is achieved after $1 \mathrm{~h}$ ageing.

Acknowledgements: The UOW Engineering Materials Institute strategic grant financially supported this work. The use of UOW Electron Microscopy Centre facilities, in particular JEOL 7001F, which was purchased with ARC support (LE0882613) is being acknowledged. The authors are grateful to Dr. A. A. Gazder for modification of tensile stage. One of the authors (Mansur Ahmed) would like to acknowledge the University Postgraduate Award (UPA) with International Postgraduate Tuition Award (IPTA) for his PhD study.

\section{References}

[1] P.J. Bania in D. Eylon, R.R. Boyer, D.A. Koss, (Eds.), Beta Titanium Alloys in the 90's, TMS, Warrendale, PA, 1993, pp. 3-14.

[2] R.R. Boyer, Mater. Sci. Eng. A 213 (1996) 103-114.

[3] P.A. Kobryn, Casting of Titanium Alloys, A Report submitted to DTIC, USA (1996).

[4] J.D. Cotton, L.P. Clark, H.R. Phelps, JOM 58 (2006) 13-16.

[5] L. Jia, D. Xu, M. Li, J. Guo, H. Fu, Met. Mater. Int. 18 (2012) 55-61.

[6] E.R. Thompson, Annu. Rev. Mater. Sci. 12 (1982) 213-242.

[7] T. Fujita, A. Ogawa, C. Ouchi, H. Tajima, Mater. Sci. Eng. A 213 (1996) 148-153.

[8] F.H. Froes, D. Eylon, Int. Mater. Rev. 35 (1990) 162-184. 
[9] O.M. Ivasishin, D. Eylon, V.I. Bondarchuk, D.G. Savvakin, Defect Diffusion Forum 277 (2008) 177-185.

[10] C. Leyens, M. Peters, Titanium and Titanium Alloys: Fundamentals and Applications: John Wiley \& Sons, 2006.

[11] V.N. Moiseev, Met. Sci. Heat Treat. 42 (2000) 81-83.

[12] Y. Ohmori, T. Ogo, K. Nakai, S. Kobayashi, Mater. Sci. Eng. A 312 (2001) 182-188.

[13] S.-z. Zhang, Z.-q. Liu, G.-d. Wang, L.-q. Chen, X.-h. Liu, R. Yang, J. Cent. South Univ. Technol. 16 (2009) 354-359.

[14] O.M. Ivasishin, P.E. Markovsky, Y.V. Matviychuk, S.L. Semiatin, C.H. Ward, S. Fox, J. Alloys Compds 457 (2008) 296-309.

[15] S. Nag, R. Banerjee, R. Srinivasan, J.Y. Hwang, M. Harper, H.L. Fraser, Acta Mater. 57 (2009) 2136-2147.

[16] T. Furuhara, T. Maki, T. Makino, J. Mater. Process. Technol. 117 (2001) 318-323.

[17] V.N. Moiseev, Met. Sci. Heat Treat. 40 (1998) 482-485.

[18] V.N. Moiseev, N.V. Sysoeva, M.I. Ermolova, Met. Sci. Heat Treat. 38 (1996) 42-45.

[19] A.M. Parshin, S.S. Ushkov, I.I. Yarmolovich, Met. Sci Heat. Treat. 15 (1973) 313-316.

[20] N.V. Sysoeva, V.N. Moiseev, Met. Sci. Heat Treat. 44 (2002) 304-308.

[21] V.N. Moiseev, N.V. Sysoeva, T.V. Ishun'kina, Met. Sci. Heat Treat. 37 (1995) 248-250.

[22] V.V. Shevel'kov, Met. Sci. Heat Treat. 34 (1992) 534-539.

[23] O.M. Ivasishin, P.E. Markovsky, JOM 48 (1996) 48-52.

[24] D. Savvakin, A. Carman, O. Ivasishin, M. Matviychuk, A. Gazder, E. Pereloma, Metall. Mater. Trans. A 43 (2012) 716-723.

[25] B.D. Cullity, S.R. Stock, Elements of x-ray diffraction, third eds., Prentice Hall, 2001.

[26] L. Lutterotti, P. Scardi, J. Appl. Crystallogr. 23 (1990) 246-252.

[27] M. Ahmed, D.G. Savvakin, O.M. Ivasishin, E.V. Pereloma, Mater. Sci. Eng. A 576 (2013) 167-177.

[28] R.E. Smallman, K.H. Westmacott, Philos. Mag. 2 (1957) 669-683.

[29] J.K. Fan, H.C. Kou, M.J. Lai, B. Tang, H. Chang, J.S. Li, Mater. Sci. Eng. A 584 (2013) 121132.

[30] A. Sarkar, S. Roy, S. Suwas, Mater. Charact. 62 (2011) 35-42.

[31] O.M. Ivasishin, P.E. Markovsky, S.L. Semiatin, C.H. Ward, Mater. Sci. Eng. A 405 (2005) 296-305.

[32] V.N. Moiseev, N.V. Sysoeva, I.G. Polyakova, Met. Sci. Heat Treat. 40 (1998) 107-111.

[33] I. Weiss, S.L. Semiatin, Mater. Sci. Eng. A 243 (1998) 46-65.

[34] A. Szkliniarz, W. Szkliniarz, Solid State Phenom. 176 (2011) 139-148.

[35] N. Wain, X.J. Hao, G.A. Ravi, X. Wu, Mater. Sci. Eng. A 527 (2010) 7673-7683. 
[36] C.-M. Sung, M.-F. Tai, Int. J. Refract. Met. Hard Mat. 15 (1997) 237-256.

[37] P.G. Oberson, Z.W. Wyatt, S. Ankem, Scr. Mater. 65 (2011) 638-641.

[38] G. Neumann, C. Tuijn, Self-diffusion and Impurity Diffusion in Pure Metals: Handbook of Experimental Data: Elsevier Science, 2011.

[39] H. Nakajima, K. Ogasawara, S. Yamaguchi, M. Koiwa, Mater. Trans. 31 249-254.

[40] R.J. Talling, R.J. Dashwood, M. Jackson, S. Kuramoto, D. Dye, Scr. Mater. 59 (2008) 669672.

[41] M. Ahmed, A. Gazder, D. Savvakin, O. Ivasishin, E. Pereloma, J. Mater. Sci. 47 (2012) 7013-7025.

[42] O.P. Karasevskaya, O.M. Ivasishin, S.L. Semiatin, Y.V. Matviychuk, Mater. Sci. Eng. A 354 (2003) 121-132.

[43] R.R. Boyer, H.J. Rack, V. Venkatesh, Mater. Sci. Eng. A 243 (1998) 97-102.

[44] W. Nie, X. Wang, S. Wu, H. Guan, C. Shang, Sci CHINA Technol. Sci. 55 (2012) 1791-1796.

[45] A. Kumar, S.B. Singh, K.K. Ray, Mater. Sci. Eng. A 474 (2008) 270-282.

[46] F.H. Samuel, Mater. Sci. Eng. 92 (1987) L1-L4.

[47] A. Bag, K. Ray, E. Dwarakadasa, Metall. Mater. Trans. A 30 (1999) 1193-1202.

[48] H. Paruz, D.V. Edmonds, Mater. Sci. Eng. A 117 (1989) 67-74.

[49] S.L. Raghunathan, A.M. Stapleton, R.J. Dashwood, M. Jackson, D. Dye, Acta Mater. 55 (2007) 6861-6872. 